\title{
A novel follicle culture system markedly increases follicle volume, cell number and oestradiol secretion
}

\author{
G Wycherley, D Downey, M T Kane and A C Hynes \\ Department of Physiology, National University of Ireland, Galway, University Road, Galway, Ireland \\ Correspondence should be addressed to A C Hynes; Email: ailish.hynes@nuigalway.ie
}

\begin{abstract}
This study reports a novel, simple method for culture of mouse follicles which results in follicles with cell numbers similar to in vivo fully grown follicles. Using this method, follicles (180-240 $\mu \mathrm{m}$ in diameter) were cultured in a $100 \mu \mathrm{l}$ inverted drop of medium without oil and compared with culture in upright drops with and without a mineral oil overlay. Follicles, isolated from $\mathrm{C} 57 \mathrm{BL} / 6 \times \mathrm{CBA} / \mathrm{ca}$ crossbred and MF1 inbred mice, were cultured individually at $37^{\circ} \mathrm{C}$ in 96-well round-bottomed suspension cell tissue culture plates for 6 days. Follicles grown in the inverted drop culture system reached a markedly higher final diameter (means \pm S.E.M.; $471 \pm 6.0 \mu \mathrm{m})$ as compared with the upright with oil $(363 \pm 2.7 \mu \mathrm{m}$ ) and without oil $(358 \pm 4.0)$ systems. There was no significant effect of mouse strain on follicle diameter. Follicular secretion of oestradiol and lactate into the medium was measured on days 2,4 and 6 of culture. Secretion of oestradiol per follicle on day 6 was $2.49 \pm 0.45 \mathrm{ng}$ in the inverted and $0.90 \pm 0.17 \mathrm{ng}$ in the upright without oil system $(P<0.001)$. Follicular secretion of lactate on a per unit of follicle volume basis remained constant in the inverted system over days 2,4 and 6 and was less $(P<0.001)$ than secretion in both the upright with and without oil systems. Follicle cell proliferation was markedly increased in the inverted as compared with the upright with oil system; the increases in cell numbers were significant on day $3(P<0.01)$ and on all subsequent days $(P<\mathbf{0 . 0 0 1})$. These results are discussed in relation to the supply of oxygen to the follicle in culture. Reproduction (2004) 127 669-677
\end{abstract}

\section{Introduction}

In vitro culture of ovarian follicles provides a powerful model for the study of follicle growth and ovulation. In a landmark paper, Nayudu \& Osborn (1992) established a culture system which enabled intact preantral mouse ovarian follicles to be grown to approximately $400 \mu \mathrm{m}$ in diameter. This system and the adaptations made to it by other workers have been reviewed by Nayudu et al. (2001).

There are a number of lines of evidence which strongly suggest that in vitro follicle culture conditions are not yet optimal. Fully grown mouse follicles in vivo reach diameters of approximately $500 \mu \mathrm{m}$ (reviewed by Murray \& Spears 2000) whereas in vitro grown follicles generally reach approximately $400 \mu \mathrm{m}$ (Spears et al. 1996, 1998, Murray et al. 1998). In addition, the developmental competence of oocytes from cultured follicles is far below what one would expect from healthy in vivo produced mouse follicles (Spears et al. 1994). There have also been very few live births from in vitro grown oocytes using follicle culture systems (reviewed by Smitz \& Cortvrindt 2002). The greatest degree of success in producing live births from in vitro grown oocytes has being achieved using organ culture of whole ovaries of newborn mice followed by culture of isolated cumulus-oocyte complexes (Eppig \& O'Brien 1996, O'Brien et al. 2003). However, since their method does not involve whole follicle culture, it is not a useful model for the study of follicle growth and maturation.

In most follicle culture systems the follicle is cultured, under a gas phase of about $20 \%$ oxygen, at the bottom of a culture well in which the medium is covered by an oil overlay. Since a fully grown mouse follicle contains about 50000 cells (Pedersen, 1970), the question arises as to whether oxygen diffusion through the oil overlay down to the bottom of the culture well is capable of supplying enough oxygen for follicular growth. In the work reported here, we investigated the use of a novel inverted system without oil for follicle culture and compared it with upright systems with and without an oil overlay (Fig. 1). In this inverted system, culture is carried out with the culture dish in the upside down or inverted position. Since the follicle in the inverted system lies at the medium/gas interface during culture, one effect of the inverted system should be to maximize access of oxygen to the cultured follicle. 


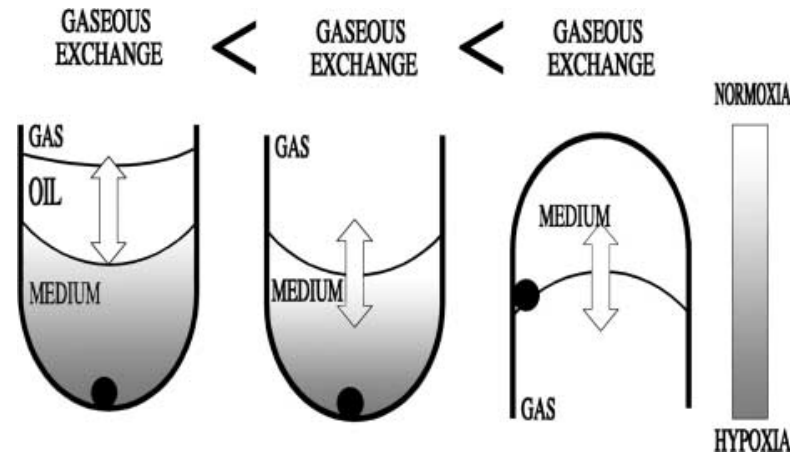

Figure 1 Diagrammatic representation of the three follicle culture systems including the proposed oxygenation state of follicles cultured in each system.

\section{Materials and Methods}

\section{Animals}

$\mathrm{C} 57 \mathrm{BL} / 6 \times \mathrm{CBA} / \mathrm{ca} \mathrm{F} 1$ generation and inbred MF1 mice were used for these experiments. Mice were housed under a photoperiod of $14 \mathrm{~h}$ light: $10 \mathrm{~h}$ darkness and provided with food and water ad libitum.

\section{Follicle isolation}

Follicles were isolated as previously described (Boland et al. 1993) with minor modifications. Briefly, prepubertal mice aged between 23 and 26 days of age were killed by cervical dislocation and their ovaries were removed to a $35 \mathrm{~mm}$ Petri dish (Nunc A/S, Roskilde, Denmark) with $4 \mathrm{ml}$ Leibovitz L-15 medium (Sigma-Aldrich, Poole, Dorset, UK) cell culture grade supplemented with $3 \mathrm{mg} / \mathrm{ml}$ bovine serum albumin (fraction $\mathrm{V}$; Sigma-Aldrich) at $37^{\circ} \mathrm{C}$. Ovaries were cleaned of any surrounding tissue and individual follicles (diameters from 180 to $240 \mu \mathrm{m})$ were dissected out with acupuncture needles (Carbo EZY-5, 0.22-0.30 gauge, $25 \mathrm{~mm}$ in length; Helio Medical Supplies, Santa Clara, CA, USA), attached to microbiological loop holders. Only follicles with an intact theca layer with some stromal cells attached and no visible signs of atresia were used for culture.

\section{Follicle culture}

Follicles were cultured in 96-well round-bottomed suspension cell tissue culture plates (Sarstedt, Drinagh, Co. Wexford, Ireland) in $100 \mu \mathrm{l}$ droplets of $\alpha$-minimal essential medium (Sigma-Aldrich) supplemented with 5\% female mouse serum, human follicle-stimulating hormone $\mathrm{FSH}$; $5 \mathrm{IU}$ or $1 \mathrm{IU} / \mathrm{ml}$; National Hormone Pituitary Program, Harbor-UCLA Medical Centre, Torrance, CA, USA) and $25 \mu \mathrm{g} / \mathrm{ml}$ ascorbic acid (Sigma-Aldrich). Serum was prepared as described by Boland et al. (1993) except that the mice were killed by carbon dioxide asphyxiation and blood was collected from the heart immediately postmortem.
All media were made up weekly from powdered stocks with Milli-Q water from a Milli-Q system (Millipore, Watford, Herts, UK). Follicles were cultured in three ways depending on the experiment: in a $100 \mu$ ldrop overlaid with $70 \mu \mathrm{l}$ mineral oil (upright with oil system), a $100 \mu \mathrm{l}$ drop not overlaid (upright without oil system) or a $100 \mu \mathrm{l}$ drop with the plate turned upside-down without oil (inverted system). When the plate was inverted, the follicles came to rest and were cultured sitting on the medium/gas interface, thus maximizing gaseous exchange. The medium remained in the wells because of surface tension. Sterile Milli-Q water $(100 \mu \mathrm{l})$ was put into the first and last row of wells and into the spaces between the wells to ensure a humid atmosphere over the culture medium. Follicle diameters were measured daily on a Nikon Axiovert inverted microscope (The Micron Optical Co. Ltd, County Wexford, Ireland) at $100 \times$ and follicles were transferred every other day to a fresh row of wells. For any follicles that were not spherical, the average of the long and short axes was taken as the diameter. Follicles grown in inverted plates were turned right side up for transfer and measurement. All plates were cultured in a humidified incubator under a $5 \% \mathrm{CO}_{2}$ atmosphere at $37^{\circ} \mathrm{C}$.

\section{Oestradiol assay}

Follicle-conditioned medium was collected on each day of transfer and stored at $-70{ }^{\circ} \mathrm{C}$ for oestradiol analysis. Oestradiol production was measured for individual follicles using an enzyme immunoassay (Tamate et al. 1997) according to the manufacturer's instructions (BioResearch Ireland, Dublin, Ireland). Serial dilutions of the sample were made in a matrix provided by the manufacturer and all dilutions were parallel to the standard curve. Absorbance was read on an Anthos 2010 microplate reader (AGB, Dublin, Ireland) at $492 \mathrm{~nm}$ and oestradiol values were read from a standard curve.

\section{Quantification of the number of cells per follicle in vitro and in vivo}

At the end of every $24 \mathrm{~h}$ in culture a sample of follicles was removed, washed once in phosphate-buffered saline and treated with $5 \mathrm{mg} / \mathrm{ml}$ collagenase type I (SigmaAldrich) at $37^{\circ} \mathrm{C}$ for $5 \mathrm{~min}$. At the end of the $5 \mathrm{~min}$ an equal volume of trypsin-EDTA solution (trypsin $0.5 \mathrm{~g} / \mathrm{l}$, EDTA $0.2 \mathrm{~g} / \mathrm{l} ; 1 \times$ liquid; GibcoBRL, Life Technologies, Paisley, Strathclyde, UK) was added and incubated for a further $5 \mathrm{~min}$. The clumped cells were then pipetted gently to form a single cell suspension. The suspension was centrifuged for $3 \mathrm{~min}$, the supernatant discarded and the pellet re-suspended in an appropriate volume of phosphatebuffered saline for counting using a haemocytometer. Because all the cells from intact follicles were counted, cell counts include both granulosa and theca cells.

For purposes of comparison with in vitro grown follicles, follicles grown in vivo were dissected out of adult mice in a similar fashion to that described above except 
that the largest follicles (3-4 per ovary) were chosen and great care was taken to remove as much stroma as possible from the follicle. The dispersion and counting procedure was the same as for in vitro grown follicles.

\section{Measurement of lactate}

Lactate production was measured using a colorimetric lactate diagnostic kit (Sigma-Aldrich) based on the conversion of lactate to pyruvate and hydrogen peroxide by lactate oxidase. Sample volume was $10 \mu \mathrm{l}$, reagent volume was $1 \mathrm{ml}$ and the absorbance was measured at $540 \mathrm{~nm}$ on a Pharmacia Ultraspec 4000 (Amershampharmacia Biotech, Cambridge, UK).

\section{Statistical analysis}

All experiments were analysed by analysis of variance in which the effects of culture treatment were examined separately for either each day of culture or every second day of culture. Where appropriate, means were further analysed by the Bonferroni-Dunn post hoc test.

\section{Results}

\section{Experiment 1: effect of the culture system on follicle growth, and oestradiol and lactate production of follicles from purebred MF1 mice}

Follicles from MF1 mice were cultured for 6 days in the three culture (upright with oil, upright without oil and inverted) systems. FSH concentration was $5 \mathrm{IU} / \mathrm{ml}$. Follicle diameters were measured daily. Oestradiol and lactate secretion into the culture medium was measured every second day.

The effects of the culture system on follicle growth and secretion of oestradiol and lactate into the culture medium are shown in Fig. 2. Examination of the effects of the culture system on follicle diameter (Fig. 2a) and volume (Fig. 2b) showed that the inverted system significantly increased follicle growth on days $2-6(P<0.001)$. The percentage increases in follicle diameter and volume on day 6 in the inverted system were $29.6 \%$ and $120 \%$ as compared with the upright with oil system. There were no significant differences between the two upright systems.

Oestradiol content of the culture medium was used as a measure of oestradiol secretion by the follicles. While data are presented for all three systems (Fig. 2c and d), since oestradiol is soluble in oil, oestradiol content of the medium as a measure of follicular oestradiol secretion is only valid for the oil-free upright and inverted systems and statistical comparisons were only made for these two systems. On day 6, oestradiol secretion per follicle into the culture medium (Fig. 2c) was markedly increased $(+177 \%)$ in the inverted system as compared with the upright without oil system $(P<0.01)$. There was no significant difference between inverted and upright without oil systems at days 2 or 4 .
When oestradiol secretion was expressed on a per $\mathrm{nl}$ follicle basis, there was no significant difference between inverted and upright without oil systems at any day of culture, indicating that the increased secretion in the inverted system on day 6 relative to the upright without oil system was due mainly to the increase in follicle volume. However, the capacity to secrete oestradiol per unit volume of follicle increased linearly with duration of culture in both inverted $(P<0.001)$ and upright $(P<0.05)$ without oil systems. Interestingly, the increase in day 6 secretion as compared with day 2 secretion was much greater for the inverted (5.6-fold increase) than for the upright without oil system (2.6-fold increase).

Lactate production and secretion is an indicator of anaerobic metabolism. Lactate secretion into the medium per follicle increased in both the upright systems on day 4 as compared with day 2 but either leveled off or decreased again on day 6 (Fig. 2e). However, in the inverted system, secretion per follicle increased on both day 4 and day 6 . The relative effect of the culture systems on lactate secretion per follicle varied with the day of culture; on day 2 , secretion in the inverted system was significantly lower than that in the upright with oil system $(P<0.05)$, not significantly different on day 4 and significantly greater than both upright systems $(P<0.01)$ on day 6 .

When lactate secretion was expressed on a per $\mathrm{nl}$ follicle basis, the increase in lactate secretion per follicle with day of culture in the inverted system can be seen to have been totally due to the increase in follicle volume (Fig. 2f). Secretion on a per unit volume basis remained constant in the inverted system over days 2, 4 and 6 and was significantly $(P<0.001)$ less than secretion in both the upright systems. There was no significant difference between the two upright systems. There was a tendency in both upright systems for secretion of lactate per $\mathrm{nl}$ follicle to decrease with day of culture; in the upright with oil system, secretion at days 4 and 6 was decreased significantly $(P<0.01)$ as compared with secretion at day 2 , and in the without oil system, secretion at day 6 was significantly decreased as compared with secretion at day 4 .

The results of this experiment showed that the inverted culture system, as compared with either of the two upright systems, markedly improved follicle growth (as determined by diameter and volume) and oestradiol secretion, and decreased lactate production (as expressed on a per unit volume basis).

\section{Experiment 2: effect of the culture system on follicle cell proliferation}

Follicles from purebred MF1 mice were cultured for 6 days in the two culture systems (inverted and upright with oil). FSH concentration was $1 \mathrm{IU} / \mathrm{ml}$. Follicle cell numbers were measured daily. The effect of the culture system on cell proliferation of follicles is shown in Fig. 3. Data are also shown for cell numbers of large in vivo grown follicles from adult mice. The mean follicle diameter of in vivo 
(a)



(c)

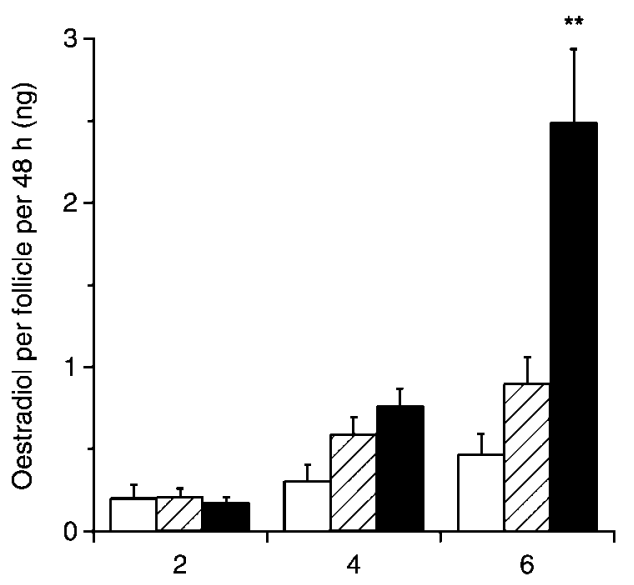

(e)

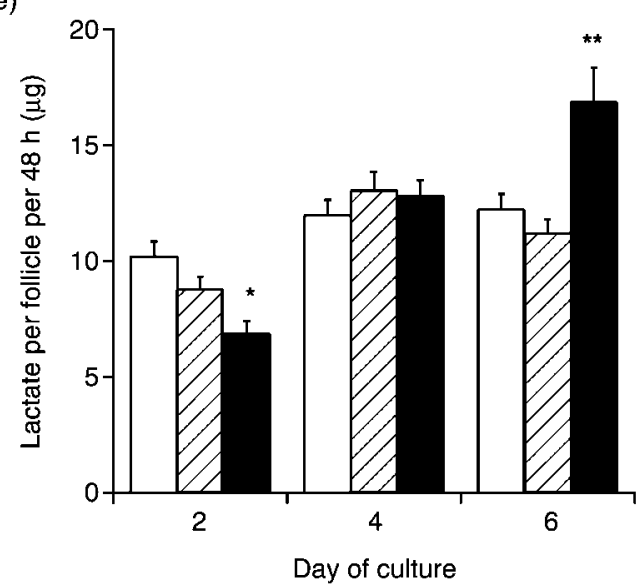

(b)

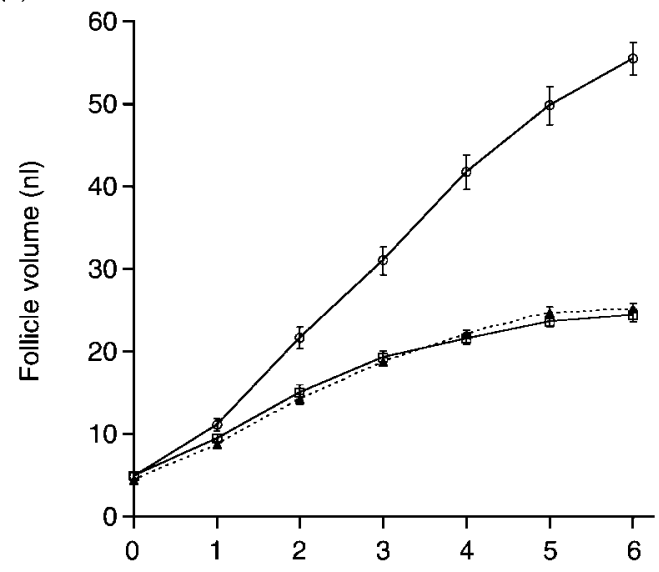

(d)

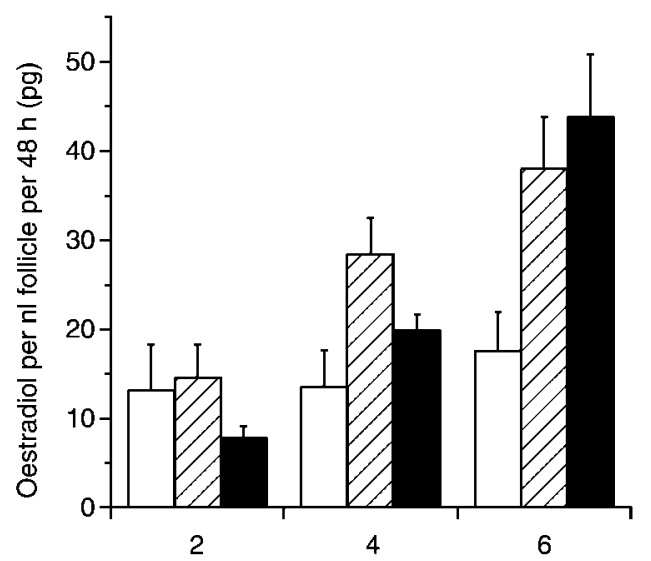

(f)

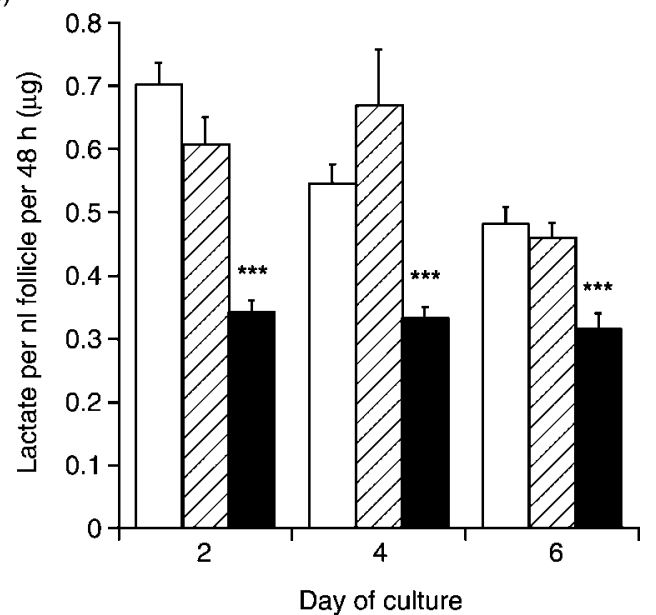

Figure 2 Effects of the culture system on growth and secretion of oestradiol and lactate by follicles from MF1 purebred mice. Values are means \pm S.E.M. ( $a$ and b) Effect of the culture system on (a) follicular diameter and (b) volume. Culture systems are shown as follows: inverted system ( $O$ and solid lines), upright without oil ( $\square$ and solid lines) and upright with oil ( $\boldsymbol{\Lambda}$ and broken lines); $n=25-26$ follicles for each system. The inverted system was significantly different from the upright systems on all days of culture for both diameter and volume (day $1, P<0.05$; days $2-6, P<0.001$ ). (c and d) Effect of the culture system on oestradiol secretion into the medium with secretion expressed both (c) per follicle and (d) per $\mathrm{nl}$ follicle over $48 \mathrm{~h}$. Culture systems are shown as follows: inverted system (solid bars), upright without oil (hatched bars) and upright with oil (open bars); $n=9-11$ follicles for each system. Significant differences between inverted and upright system without oil, $* * P<0.01$, because oestradiol is soluble in oil, data for the upright with oil treatment were not included in the statistical analysis. (e and f) Effect of the culture system on lactate secretion into the medium with secretion expressed both (e) per follicle and (f) per $\mathrm{nl}$ follicle. Culture systems are shown as in (c and d); $n=16-18$ follicles for each system. Significant difference from the upright culture systems, $* P<0.05, * * P<0.01$, $* * * P<0.001$. 

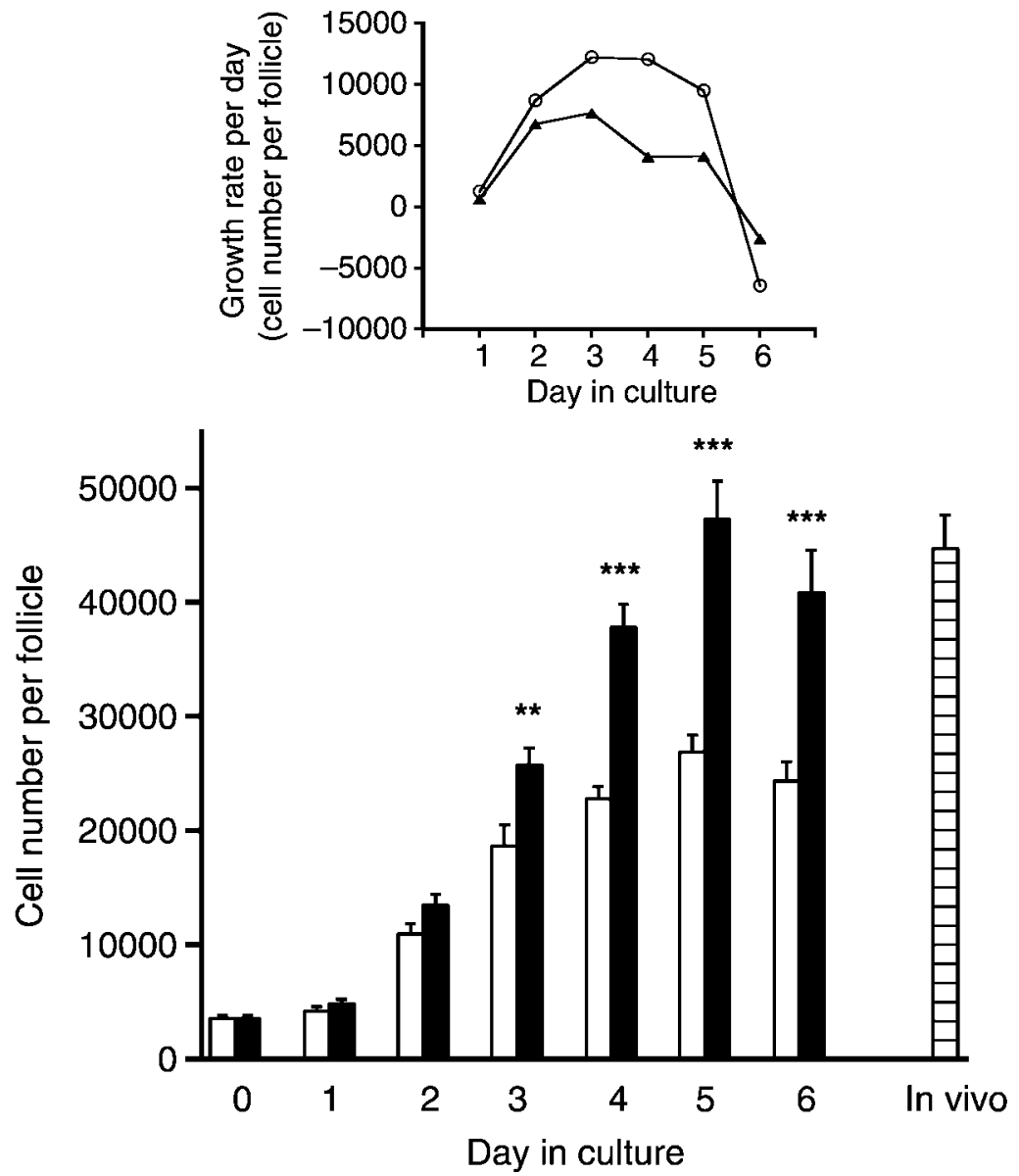

Figure 3 Effects of the culture system on cell proliferation of follicles from MF1 purebred mice. Values are means \pm S.E.M follicle cell number. Treatment groups are shown as follows: inverted system (solid bars), upright with oil (open bars) and in vivo grown follicles from adult mice (horizontally hatched bar); $n=10-15$ follicles for inverted and upright systems and 7 for the in vivo grown system. Inset: growth rate of cultured follicles per day (cell numbers per follicle); inverted system $(\mathrm{O})$ and upright with oil $(\mathbf{\Lambda})$. Growth rate was calculated as the difference in mean cell numbers between successive days. The inverted system was significantly different from the upright with oil system, ${ }_{* *} P<0.01, * * * P<0.001$. Cell numbers of in vitro grown follicles at days 5 and 6 did not differ from the in vivo grown follicles from adult mice. grown follicles was $525.9 \pm 12.7 \mu \mathrm{m}$. Cell proliferation was markedly increased in the inverted system as compared with the upright with oil system; the increases in cell numbers were significant on day $3(P<0.01)$ and on all

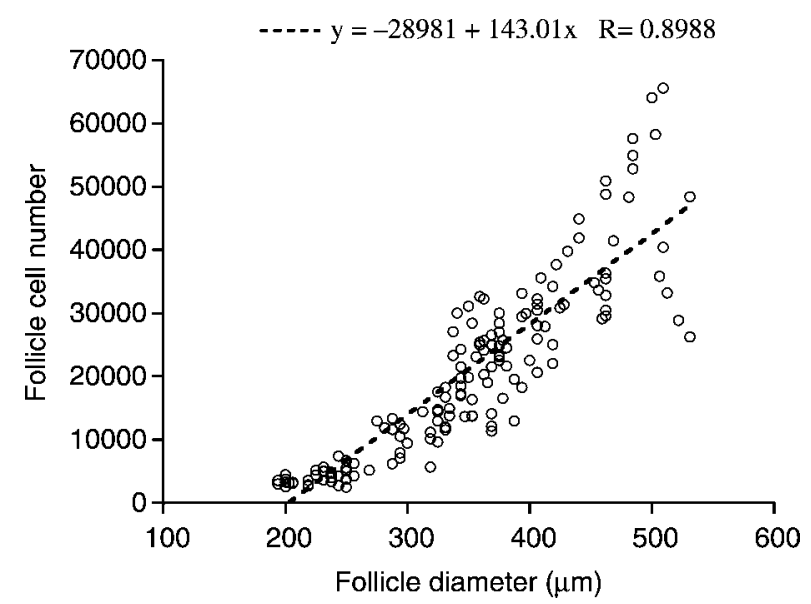

Figure 4 Relationship between follicle cell number and follicle diameter. These data are taken from day- 6 cell counts of all in vitro cultured follicles in Fig. 3. There was a significant linear relationship between cell number per follicle and follicle diameter $(P<0.001$ and $\left.R^{2}=0.808\right)$. subsequent days $(P<0.001)$ with a 1.76 -fold increase in cell numbers on day 5 . Cell numbers of in vitro grown follicles in the inverted system at days 5 and 6 did not differ from the in vivo grown follicles from adult mice. Growth rate per day (calculated as the difference in cell numbers between successive days) in the inverted system increased rapidly up to day 3, was maintained from day 3 to day 5 and then decreased markedly from day 5 to day 6 (Fig. 3 inset). In contrast, growth rate in the upright with oil system increased up to day 3 but then declined markedly from day 3 to day 6 .

There was a linear relationship between cell numbers and follicle diameter (Fig. 4); the $\mathrm{R}^{2}$ value was 0.808, indicating that about $81 \%$ of the statistical variation in follicle cell numbers could be accounted for by follicle diameter.

The result of this experiment showed that the inverted system markedly increased follicle cell proliferation as compared with the upright with oil system.

\section{Experiment 3: effects of mouse strain and culture system on follicle growth}

Follicles from purebred MF1 and crossbred C57BL/ $6 \times$ $\mathrm{CBA} / \mathrm{ca}$ F1 mice were cultured for 6 days in the two 


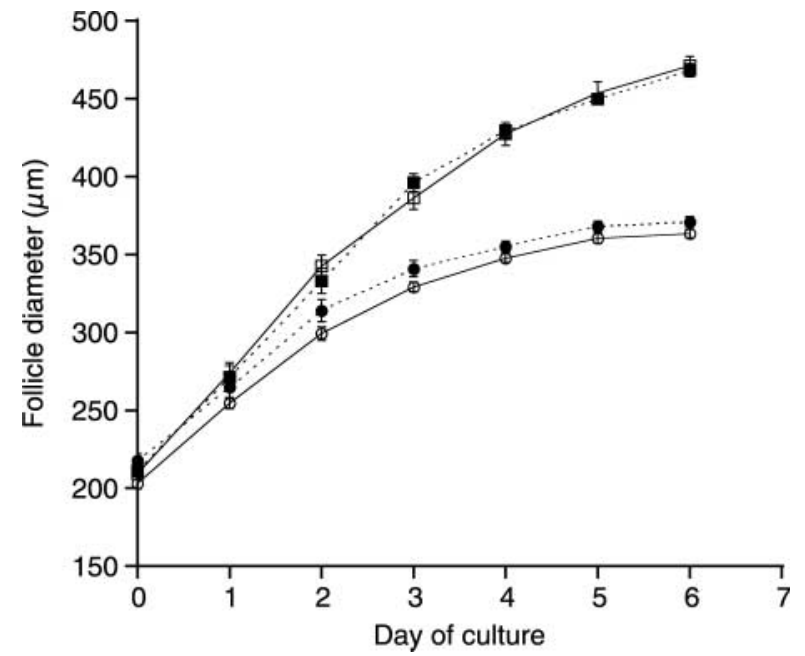

Figure 5 Effect of strain of mouse on follicular growth in the two different culture systems. Values are means \pm S.E.M. follicle diameter. Treatments are shown as follows: inverted system in MF1 mice ( $\square$ ), inverted system in $\mathrm{C} 57 \mathrm{BL} / 6 \times \mathrm{CBA} / \mathrm{ca}$ mice $(\mathbf{\square})$, upright with oil system in MF1 mice (O) and upright with oil system in $\mathrm{C} 57 \mathrm{BL} / 6 \times$ CBA/ca mice $(\bullet) ; n=22-31$ follicles per treatment. There was no significant effect of mouse strain at any stage of culture. Culture systems were significantly different at all stages $(P<0.05$ at day 1 and $P<0.001$ at days 2-6).

culture systems (inverted and upright with oil). FSH concentration was $1 \mathrm{IU} / \mathrm{ml}$. Follicle diameters were measured daily. The effect of mouse strain and culture system on follicle growth is shown in Fig. 5. Follicular size was significantly greater in the inverted system as compared with the upright with oil system at all stages ( $P<0.05$ for day 1 and $P<0.001$ for days 2-6). There was no significant interaction between culture system and strain of mice, indicating that the inverted system was equally beneficial for growth of both purebred MF1 and crossbred C57BL/ $6 \times \mathrm{CBA} / \mathrm{ca}$ follicles.

Follicles from the crossbred mice were significantly $(4.0 \%, P<0.05)$ larger than purebred mice at the start of culture (day 0) but were not significantly different at any culture stage.

The result of this experiment showed that, in both inbred and crossbred mouse strains, the inverted system produced markedly increased follicle growth as compared with the upright with oil system.

\section{Experiment 4: effect of FSH concentration on growth of follicles from purebred MF1 mice}

Because the level of $\mathrm{FSH}$ used in experiment 1 was $5 \mathrm{IU} / \mathrm{ml}$ but $1 \mathrm{IU} / \mathrm{ml}$ in experiments 2 and 3 , in this experiment we compared the effects of 1 and $5 \mathrm{IU} / \mathrm{ml} \mathrm{FSH}$ on the growth of MF1 mouse follicles cultured for 6 days in the inverted system. There was no significant effect of concentration of FSH at any day of culture (Fig. 6).

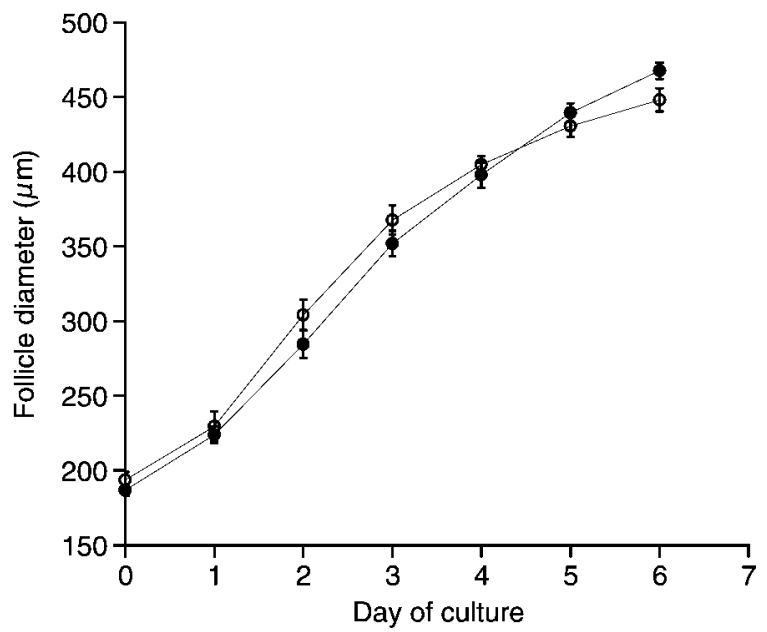

Figure 6 Effect of FSH concentration in the medium (1 IU FSH (O) and $5 \mathrm{IU}$ FSH $(\bullet)$ ) on growth of follicles from MF1 purebred mice cultured in the inverted system. Values are means \pm S.E.M. follicle diameter; $n=13$ for $1 \mathrm{IU}$ FSH and 29 for the $5 \mathrm{IU}$ FSH treatments. There was no significant effect of $\mathrm{FSH}$ at any day of culture.

\section{Discussion}

Culture of mouse whole ovarian follicles in vitro in upright culture systems involves a compromise between a drop size large enough to provide an adequate nutrient supply to the growing follicle and accessibility of oxygen to the follicle lying at the bottom of a large culture drop. The vast majority of researchers use drop sizes between 20 and $40 \mu \mathrm{l}$; in a survey of 18 papers on mouse follicular culture published between 1992 and 2002, we found that this was the range of drop sizes used with only three exceptions, Spears et al. (1996) with a drop size of $100 \mu \mathrm{l}$, Nayudu \& Osborn (1992) with a drop size of $150 \mu \mathrm{l}$ and Rose et al. (1999) with a drop size of $250 \mu \mathrm{l}$. Small drop sizes of 20$40 \mu \mathrm{l}$ may pose serious problems of inadequate nutrient supply, particularly when growth of large follicles with diameters of $400 \mu \mathrm{m}$ and cell numbers of about 40000 cells is involved; in the case of a $20 \mu$ ldrop, this would give a cell density of $2 \times 10^{6}$ cells $/ \mathrm{ml}$. In such cases, problems of nutrient supply are probably only partly alleviated by changing the medium every second day. However, use of relatively large drop sizes of $100-250 \mu$ l in upright systems may pose a different type of problem due to limited diffusion of oxygen to the follicle at the bottom of the culture well; this problem is likely to be exacerbated by the barrier effect of an oil overlay (Nayudu et al. 2001). A culture system which uses an inverted culture drop of a relatively large size $(100-250 \mu \mathrm{l})$ in which the follicle sits on the medium/gas interface (Fig. 1) offers the advantage of overcoming both the problem of limited nutrient availability due to a small drop size and the problem of relatively long diffusion distances for oxygen at the bottom of an upright well. An alternative to the inverted system is the system used by Qvist et al. (1990) in which follicles were grown in culture dishes with a gas permeable Petriperm base and the medium just covered the follicle. 
The results described here using a drop size of $100 \mu \mathrm{l}$ have demonstrated that an inverted culture system without oil results in superior growth of mouse follicles as compared with upright systems with or without an oil overlay; this superiority was obvious whether the measure of follicular growth was volume (2.2-fold), cell number (1.7fold) or oestradiol secretion (2.8-fold). The mean cell number per follicle by day 5 of culture in the inverted system (47 250) was greater than the mean cell number of the large follicles from adult mice (44 629; Fig. 3). It also compares favourably with the cell number of 50000 reported by Pedersen (1970) for large type 7 mouse preovulatory follicles about $13 \mathrm{~h}$ before the expected time of ovulation.

The most probable explanation for the improved growth in the inverted system is improved oxygenation of the follicles (Fig. 1). The distance between the bottom of the well in a 96-well round-bottomed culture plate and the medium/gas phase interface in our upright system without oil is $4.9 \mathrm{~mm}$. Diffusion of oxygen in aqueous media is very slow with a diffusion coefficient of about $0.00003 \mathrm{~cm}^{2} / \mathrm{s}$ at $37^{\circ} \mathrm{C}$ (Himmelbau 1964). In considering the supply of oxygen to follicles in an upright culture system, the important question is whether the oxygen consumption of a follicle at the bottom of a well is balanced by the flux of oxygen down from the top of the drop. The oxygen concentration in the medium surrounding the follicle must be maintained at a level adequate to allow an uptake of oxygen by the follicle at least equal to normal follicular oxygen consumption. There appears to be no information available in the literature on what is the optimal concentration of dissolved oxygen in the medium for follicular growth; however, for a number of cell types, optimal levels of dissolved oxygen in the vicinity of cultured cells are in the region of $25-50 \%$ air saturation, i.e. $25-50 \%$ of that in medium fully equilibrated with room air (Spier \& Griffiths 1983). Since some follicle diameters are up to $500 \mu \mathrm{m}$, it is probable that the optimal dissolved oxygen concentration for follicular growth is at the upper end of that range or possibly even higher.

The flux of oxygen from the medium/gas interface to the medium in the vicinity of the follicle will depend on the difference in concentration of oxygen at the top and bottom of the drop; if oxygen consumption by the follicle markedly lowers oxygen partial pressure and concentration at the bottom of the drop, this will result in an increased diffusional flux of oxygen. However, this lower oxygen concentration in the vicinity of the follicle may be insufficient to adequately oxygenate follicular cells, particularly cells at the interior of the follicle.

If one assumes that the concentration of oxygen at the bottom of the drop is $50 \%$ of that at the medium/gas phase interface (where the medium should be in equilibrium with the oxygen in the gas phase), i.e. about $50 \%$ air saturation, it is possible to calculate the maximum possible flux for that situation in our upright without oil system as follows, based on the flux equation (Stein 1990); $\mathrm{J}=\mathrm{DA}\left(\mathrm{S}_{\mathrm{I}}-\mathrm{S}_{\mathrm{II}}\right) / \mathrm{d}$, where $\mathrm{J}=$ flux of oxygen molecules $(\mu \mathrm{mol} / \mathrm{s}), \mathrm{D}=$ diffusion coefficient $\left(0.00003 \mathrm{~cm}^{2} / \mathrm{s}\right), \quad \mathrm{A}=$ cross-sectional area of the well $\left(0.322 \mathrm{~cm}^{2}\right.$; well radius is $0.32 \mathrm{~cm}$ ), $\mathrm{S}_{\mathrm{I}}=178 \mu \mathrm{mol} / \mathrm{l}$ (based on solubility of oxygen in culture medium (Hütter et al. 2002) under conditions of equilibrium with a gas phase with a $\mathrm{PO}_{2}$ of approximately $142 \mathrm{mmHg}$; this $\mathrm{PO}_{2}$ is based on a gas phase with a dry gas composition of $5 \% \mathrm{CO}_{2}$ and $95 \%$ air at $37^{\circ} \mathrm{C}$, a water vapour pressure of $47 \mathrm{mmHg}$ and an atmospheric pressure of $760 \mathrm{mmHg}$ ), $\mathrm{S}_{\mathrm{II}}=89 \mu \mathrm{mol} / \mathrm{l}, \mathrm{d}=$ distance from medium/gas phase interface to the bottom of the well $(0.49 \mathrm{~cm})$ and $\mathrm{J}=0.0000017545 \mu \mathrm{mol} / \mathrm{s}=2.36 \mathrm{nl} / \mathrm{min}$ (volume at standard temperature $\left(0^{\circ} \mathrm{C}\right)$ and pressure (760 mmHg)).

It must be emphasized that the flux of $2.36 \mathrm{nl} / \mathrm{min}$ is an upper limit; the reason for this is because the well radius is $0.32 \mathrm{~cm}$, for a follicle with a diameter of about $200 \mu \mathrm{m}$ or $0.02 \mathrm{~cm}$, much of the oxygen at the bottom of the well will still be up to $0.3 \mathrm{~cm}$ from the follicle; thus the actual effective flux is much less than $2.36 \mathrm{nl} / \mathrm{min}$. If the follicle oxygen consumption is greater than this flux, then we can expect the oxygen concentration in the vicinity of the follicle to drop below $50 \%$ of the concentration at the top of the well.

The question then arises - is this flux sufficient to meet oxygen consumption by the follicle? It is unfortunate that there seems to be no available data on oxygen consumption by mouse follicles. One approach to estimating the oxygen consumption of mouse follicles would be to take data from the literature on the oxygen consumption of mouse granulosa cells; unfortunately again such data appear to be lacking. However, there are data on the oxygen consumption of other types of mouse cells, e.g. mouse hepatocytes ( $51.4 \mathrm{nl} \mathrm{O}_{2} / 10^{6}$ cells per min; Porter \& Brand 1995) or mouse hybridoma cells $\left(130.7 \mathrm{nl} / 10^{6}\right.$ cells per min; Miller et al. 1988). If one takes the case of the day- 6 follicles at the end of culture in the inverted system (Fig. 3 ), which had a mean follicular cell number of 40783 , using data from both of these types of cells, one gets an oxygen consumption of either 2.10 or $5.33 \mathrm{nl} /$ follicle per $\min$. When it is considered that the calculated upper limit to the flux of $\mathrm{O}_{2}$ due to a $50 \%$ drop in $\mathrm{O}_{2}$ concentration from top to bottom of the culture drop is $2.36 \mathrm{nl} / \mathrm{min}$ and this limit, which is probably much greater than the actual flux to the follicle, is compared with these estimates of follicle oxygen consumption above (2.10 or $5.33 \mathrm{nl} /$ follicle per min), it would seem that the oxygen tension in the vicinity of a large cultured follicle resting at the bottom of a well in either of the upright systems is likely to be much less than a $\mathrm{PO}_{2}$ of $71 \mathrm{mmHg}$ which would correspond to $50 \%$ of the oxygen concentration at the gas phase/culture medium interface (a $\mathrm{PO}_{2}$ of about $142 \mathrm{mmHg}$ ). The resultant hypoxic conditions are made worse by the fact that, as the follicle grows, the oxygen in the vicinity of the follicle must also diffuse through the theca cell layer to supply the granulosa cells. This contrasts with the in vivo situation where diffusion of oxygen from thecal capillaries presents a rapidly renewable source of oxygen. 
The hypothesis that the follicles cultured in the upright systems suffered from hypoxia is strongly supported by our finding that lactate production per unit volume of follicle in these systems was markedly higher (in some cases up to 2 -fold higher) than in the inverted system at all stages of culture. A number of workers have found that hypoxic or anoxic conditions increase lactate production by follicles in vitro (rat follicles; Selstam \& Gafvels 1987, mouse follicles; Boland et al. 1994); similar results were found by Surwilo \& Doeg (1973) in sliced rat ovaries. The hypothesis is also supported by the fact that the growth rate (as measured by cell proliferation) of follicles cultured in the upright with oil system decreased steadily from day 3 to day 6 whereas growth rate in the inverted system was maintained from day 1 to day 5 .

However, even in the inverted system, growth rate declined drastically and became negative from day 5 to day 6 in spite of the fact that follicular diameter and volume were still increasing. A possible explanation for this is that due to poor oxygen diffusion or nutrient transport to the centre of a large day- 5 follicle, cells at the centre of the follicle begin to die even though cells in the outer layers of the follicle are still proliferating.

It is surprising that there is so little information in the literature on the effect of oxygen concentration on follicle growth and particularly on the use of gas phases with a higher oxygen concentration than $20 \%$. In long-term culture of mouse follicles, Smitz et al. (1996) and Smitz \& Cortvrindt (1998) found that a $20 \%$ oxygen gas phase was superior to $5 \%$ oxygen; a $5 \%$ concentration reduced survival of follicles and secretion of oestradiol and inhibin. Qvist et al. (1990) using Petriperm gas permeable dishes found that oxygen concentrations above $40 \%$ caused increased granulosa cell proliferation but also caused eventual necrosis of the cells and rapid disintegration of the ovum; they did not, however, specify the levels involved and did not compare $40 \%$ with $20 \%$.

In studies on mouse oocyte granulosa cell complexes isolated from preantral follicles of 12-day mice and cultured for 10 days, followed by maturation and fertilization, Eppig \& Wigglesworth (1995) concluded that concentrations of oxygen in the gas phase above $5 \%$ had a deleterious effect on oocyte development during the early stages of culture but increasing the concentration during later stages was critical in promoting normal oocyte development in vitro.

For the culture of sheep follicles, Cecconi et al. (1999) found that $5 \%$ oxygen was superior to $20 \%$; $5 \%$ oxygen in association with a high concentration of FSH stimulated development of antral follicles and increased oestradiol secretion. The apparent differences between mouse and sheep follicles are perhaps not surprising since, because of the difference in body masses of the two species, one would expect the oxygen consumption of mouse follicles on a per unit mass basis to be about 4- to 5-fold that of sheep (Porter \& Brand 1995).
One future avenue of research that must be investigated is whether the inverted system provides improved oocyte development and fertilizability as compared with the upright systems.

\section{Acknowledgements}

We thank Dr Norah Spears for help with follicle culture. This research was funded by a Health Research Board of Ireland grant to $\mathrm{A} \mathrm{CH}$.

\section{References}

Boland NI, Humpherson PG, Leese HJ \& Gosden RG 1993 Pattern of lactate production and steroidogenesis during growth and maturation of mouse ovarian follicles in vitro. Biology of Reproduction 48 798-806.

Boland NI, Humpherson PG, Leese HJ \& Gosden RG 1994 Characterization of follicular energy metabolism. Human Reproduction $\mathbf{9}$ 604-609.

Cecconi S, Barboni B, Coccia M \& Mattioli M 1999 In vitro development of sheep preantral follicles. Biology of Reproduction $\mathbf{6 0}$ 594-601.

Eppig JJ \& Wigglesworth K 1995 Factors affecting the developmental competence of mouse oocytes grown in vitro: oxygen concentration. Molecular Reproduction and Development 42 447-456.

Eppig JJ \& O'Brien MJ 1996 Development in vitro of mouse oocytes from primordial follicles. Biology of Reproduction 54 197-207.

Himmelbau DM 1964 Diffusion of dissolved gases in liquids. Chemical Reviews 64 527-550.

Hütter E, Renner K, Jansen-Dürr P \& Gnaiger E 2002 Biphasic oxygen kinetics of cellular respiration and linear oxygen dependence of antimycin A inhibited oxygen consumption. Molecular Biology Reports 29 83-87.

Miller WM, Blanch HW \& Wilke CR 1988 A kinetic analysis of hybridoma growth and metabolism in batch and continuous suspension culture: effect of nutrient concentration, dilution rate, and $\mathrm{pH}$. Biotechnology and Bioengineering 32 947-965.

Murray A \& Spears N 2000 Follicular development in vitro. Seminars in Reproductive Medicine 18 109-122.

Murray AA, Gosden RG, Allison V \& Spears N 1998 Effect of androgens on the development of mouse follicles growing in vitro. Journal of Reproduction and Fertility 113 27-33.

Nayudu PL \& Osborn SM 1992 Factors influencing the rate of preantral and antral growth of mouse ovarian follicles in vitro. Journal of Reproduction and Fertility 95 349-362.

Nayudu PL, Fehrenbach A, Kiesel P, Vitt UA, Pancharatna K \& Osborn S 2001 Progress toward understanding follicle development in vitro: appearances are not deceiving. Archives of Medical Research 32 587-594.

O'Brien MJ, Pendola JK \& Eppig JJ 2003 A revised protocol for in vitro development of mouse oocytes from primordial follicles dramatically improves their developmental competence. Biology of Reproduction 68 1682-1686.

Pedersen T 1970 Follicle kinetics in the ovary of the cyclic mouse. Acta Endocrinologica 64 304-323.

Porter RK \& Brand MD 1995 Cellular oxygen consumption depends on body mass. American Journal of Physiology 269 R226-R228.

Qvist R, Blackwell LF, Bourne H \& Brown JB 1990 Development of mouse ovarian follicles from primary to preovulatory stages in vitro. Journal of Reproduction and Fertility 89 169-180.

Rose UM, Hanssen RG \& Kloosterboer HJ 1999 Development and characterization of an in vitro ovulation model using mouse ovarian follicles. Biology of Reproduction 61 503-511.

Selstam G \& Gafvels M 1987 Oxygen dependency of preovulatory follicles from pregnant mare serum gonadotropin-treated immature rats. Acta Physiologica Scandinavica 130 483-489. 
Smitz J \& Cortvrindt R 1998 Follicle culture after ovarian cryostorage. Maturitas 30 171-179.

Smitz JEJ \& Cortvrindt RG 2002 The earliest stages of folliculogenesis in vitro. Reproduction 123 185-202.

Smitz J, Cortvrindt R \& Van Steirteghem AC 1996 Normal oxygen atmosphere is essential for the solitary long-term culture of early preantral mouse follicles. Molecular Reproduction and Development 45 466-475.

Spears N, Boland NI, Murray AA \& Gosden RG 1994 Mouse oocytes derived from in vitro grown primary ovarian follicles are fertile. Human Reproduction 9 527-532.

Spears N, de Bruin JP \& Gosden RG 1996 The establishment of follicular dominance in co-cultured mouse ovarian follicles. Journal of Reproduction and Fertility 106 1-6.

Spears N, Murray AA, Allison V, Boland NI \& Gosden RG 1998 Role of gonadotrophins and ovarian steroids in the development of mouse follicles in vitro. Journal of Reproduction and Fertility $\mathbf{1 1 3}$ $19-26$.
Spier RE \& Griffiths B 1983 An examination of the data and concepts germane to the oxygenation of cultured animal cells. Developments in Biological Standardization 55 81-92.

Stein WD 1990 In Channels, Carriers, and Pumps: An Introduction to Membrane Transport, p 33. San Diego: Harcourt Brace Jovanovich.

Surwilo BO \& Doeg KA 1973 Oxygen and glucose uptake, and lactate production in polycystic rat ovary. Endocrinology 93 652-659.

Tamate K, Charleton M, Gosling JP, Egan D, Ishikawa M, Fottrell PF \& Kane MM 1997 Direct colorimetric monoclonal antibody enzyme immunoassay for estradiol-17 beta in saliva. Clinical Chemistry 43 1159-1164.

Received 8 October 2003

First decision 7 January 2004

Revised manuscript received 19 February 2004

Accepted 10 March 2004 